\title{
Study of Breakage Tendencies of Palm Kernel, Coconut and Periwinkle Shells using Ball-Milling Process
}

\author{
J. O. Agunsoye ${ }^{1}$, J. E. Anyanwu ${ }^{1}$, S. A. Bello ${ }^{1,2^{*}}$, S. B. Hassan ${ }^{1}$ \\ ${ }^{1}$ Department of Metallurgical and Materials Engineering, University of Lagos, Akoka, Lagos State, Nigeria. \\ ${ }^{2}$ Department of Materials Science and Engineering, Kwara State University Malete, Kwara State, Nigeria.
}

\begin{abstract}
The needs for eco-friendly composites have initiated the use of agricultural wastes as possible replacements for expensive synthetic carbon and glass fillers for metal and polymer strengthening. In this study, degree of refinement of palm kernel shells, coconut shells and periwinkle shells has been investigated through ballmilling approach. Palm kernel, coconut and periwinkle shells were pulverised using disc grinder and refined using top-down approach under the same milling conditions. The particles of palm kernel, coconut and periwinkle shells obtained were analysed and their sizes were determined. Energy dispersive X-ray spectroscopic and X-ray Diffractometric analyses indicated different compositions of the examined agricultural wastes particles. Imaging sizing of the particles indicated attainment of nanoparticles when milling for 74 hours at 10 charge ratios for both carbonized and uncarbonized palm kernel, coconut and periwinkle shells. Comparison of sizes showed that uncarbonized palm kernel shell has a least grain size among other uncarbonized agricultural waste particles. Therefore, uncarbonised palm kernel shells have highest breakage tendency among others.
\end{abstract}

KEYWORDS: Degree, Refinement, Agricultural wastes, Fillers, Milling.

[Received November 29 2017; Revised March 22 2018; Accepted March 24 2018]

Print ISSN: 0189-9546 | Online ISSN: 2437-2110

\section{INTRODUCTION}

Over the years, synthetic fillers have been the dominant material for reinforcement for both metal and polymer (Allaoui et al., 2002, Baghat and Verma, 2013, Chen et al., 2007). Extensive industrial applications have been hindered due to exorbitant manufacturing costs, limited availability, fibre damage, fibre mismatch and interfacial reactions (Das et al., 2008, Goto and Uchijo, 2005, Kok, 2005, Bobic et al., 2010). Recently, material scientists and researchers have been focusing attention on natural fillers as attractive alternative to synthetic fillers for reinforcement purposes due to low cost, availability, environmental friendliness and renewability (Mohammed et al., 2015).

Palm Kernel Shells (PKS) have been assessed as partial replacement for material reinforcement in concrete and water treatment (Falade, 1992, Okoroigwe et al., 2014). It has been characterised and reported to possess organic compounds (source of carbons and nitrogen) and minerals matter (silicates, oxides, etc) suitable for material fillers in construction and absorption industries (Festus et al., 2012, Alengaram et al., 2010). Moreover, potentials of coconut and periwinkle shells (PS) for reinforcing polymer and metals have been found in literatures.

Proper and profitable utilisation of agricultural waste will reduce the negative impacts of poor waste disposal such as air pollution caused by burning of agricultural wastes (palm kernel shells). This process leads to release of harmful gases (methane, black smoke) that could cause respiratory problem (Romulo, 2013). Using the waste could also advance the knowledge of local entrepreneurship and create job for youths through Nigerian Government Local Content Policy.

*Corresponding author's e-mail address: adekunleshaafiu@gmail.com
Many natural reinforcements have been used by researchers (Ibhadode and Dagwa, 2008b, Nwaobakata and Agunwamba, 2014, Ademoh and Adeyemi, 2015, Ibhadode and Dagwa, 2008a, Yawas et al., 2016) for composite development, the detailed synthesis of such fillers is very scarce though recently; (Bello et al., 2015a) studied the effects of charge ratios and milling durations on particles sizes of coconut shell nanoparticles. Similar studies on other natural fillers namely PKS and PS are scarce if found at all. In this work, attempt has been made to study and compare ball-milling breakage tendencies of three selected agricultural wastes namely PKS, PS and coconut shells (CNS).

Strengthening mechanism of particle reinforced composites depends on particle size, particle weight fraction, interfacial adhesion between the particles and matrix. Refinement of particle grains increases the particle concentration within a matrix and reduces the inter-planar spacing among particles within the matrix. Consequently, the composites packing densities increase and limit the dislocation movement within the matrix in metallic composites. Similarly, craze formation leading to shear yielding in polymeric composites is reduced due to particle refinement. Similar explanation has been found in (Lucas et al., 2011, William, 2007, Bello et al., 2017b).

\section{MATERIALS AND METHODS}

The palm kernel, coconut and periwinkle shells used for this study were procured from the Umungbor Umuegwu Ekwerazu in Ahiazu Local Government Area of Imo State. Equipment used includes disc grinder, electric furnace, crucibles, digital weighing scale, tumbler ball mill, set of sieves with a sine shaker, Transmission Electron Microscope doi: http://dx.doi.org/10.4314/njtd.v15i3.5 
(TEM) and X-Ray Diffractometer (XRD). $5 \mathrm{~kg}$ each of palm kernel, coconut and periwinkle shells were rinsed and dried at 6 hours per day for four weeks at $120^{\circ} \mathrm{C}$ using Shel lab oven to eliminate moisture and subsequently crushed into pieces at Federal Industrial Institute of Research Oshodi (FIIRO) with the aid of Broyeur Clero Hammer Crusher, model 000T (No. 13634) and pulverised into powder with the use of disc grinder. Part of agricultural waste powders obtained was sorted into different particle sizes using set of sieves $(650-$ $45 \mu \mathrm{m}$ ) vibrated with a sine shaker for 1 hour. The powders retained below the $45 \mu \mathrm{m}$ sized sieve, were used as the feed powders for the synthesis of nanoparticles.

The remaining powders each of PKS, CNS and PS were placed in different known weight crucibles, sealed, reweighed and fired to $1100 \mathrm{oC}$ using electric furnace. This process is called carbonization. The carbonization temperature used is in line with literature (Bello et al., 2017a, Bello et al., 2016, Abiko et al., 2010). Each of the powder samples was held at this temperature for 1 hour after which the furnace was switched off and the powders were left in the furnace to cool to room temperature. Crucibles were reweighed and the carbonized samples were graded using the same set of sieves vibrated for the same time as explained in the case of uncarbonized samples.

Samples of carbonized powders retained below $45 \mu \mathrm{m}$ sized sieve, were selected for nanoparticle synthesis. Ballmilling of each powder sample was carried out for 74 hours at 10 charge ratios and 195 revolutions per minute (rpm) using balls of the same size ranges $(5-70 \mathrm{~mm})$. A tightly packed Flender Himmel electric motor powered tumbler ball mill, model A50A2043 was used. Each milled sample was analysed using XRD and TEM. Figure 1 shows the photo macrographs of agricultural wastes used in this study before and after milling.

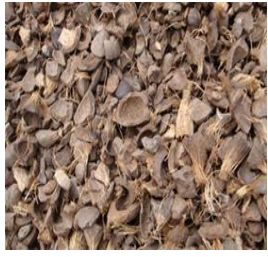

(a)

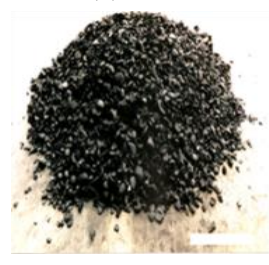

(d)

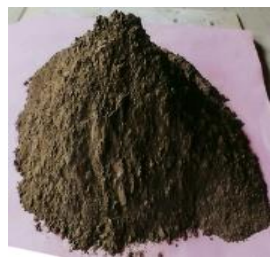

$(\mathrm{g})$

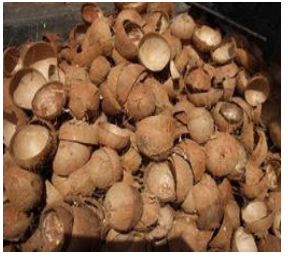

(b)

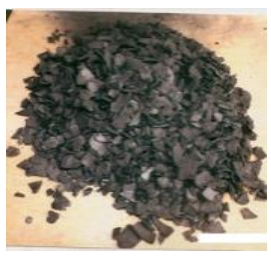

(e)

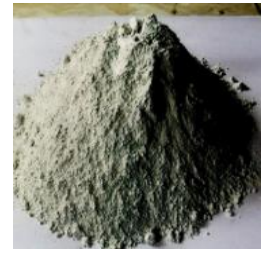

(h)

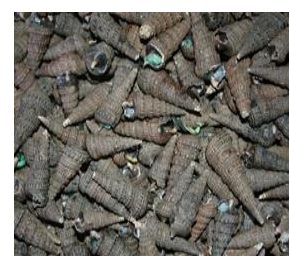

(c)

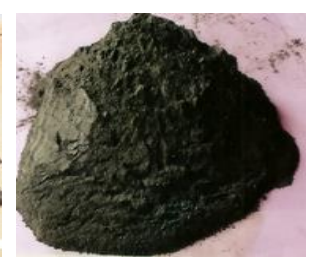

(f)
Figure 1: Natural fillers: uncarbonized (a) palm kernel (b) coconut (c) periwinkle shells; carbonized (d) palm kernel (e) coconut shell; (f) palm kernel (g) coconut shell and (h) periwinkle shell particles.

\section{RESULTS AND DISCUSSION}

Figures 2-7 reveal the TEM images, size distribution and elemental compositions of uncarbonized and carbonized agricultural waste particles obtained after 74 hours milling at 10 charge ratios. Fine particles of PKS are seen in Figure 2 forming globular networks of different sizes. The globules are attributed to coalescence of numerous fine particles due to milling ball impacts. Size determination using Gwyddion software indicates that size of PKS particles varies between 1.4 and $160.2 \mathrm{~nm}$. Energy dispersive X-ray spectroscopic analysis reveals that PKS contains both metals and nonmetals. Oxygen (O), calcium (Ca), Carbon (C) and Copper $(\mathrm{Cu})$ have higher peaks while others are the minor elements.

Most of these elements represent mineral contents such as silicate, and oxides of the PKS as indicated by X-ray diffractogram in Figure 8. Carbon (C) may represent amorphous organic compounds present in the PKS as revealed by broad peaks in Figure 8 . This observation is analogous to that of (Edmund et al., 2014). Similarly, sizes of uncarbonised CNS and PS particles vary between 0 and 191 $\mathrm{nm}$ and 0 and $148 \mathrm{~nm}$, respectively. CNS has $\mathrm{C}, \mathrm{Cu}$ and $\mathrm{O}$ as major elements as indicated by EDX in Figure 3. This agrees with XRD in Figure 9 showing C8 with the highest peak. Other elements such as $\mathrm{Cu}, \mathrm{Si}$ and $\mathrm{Mg}$ exist as silicates which are mineral components of the CNS. Bello et al., (2015) reported synthesis of CNS nanoparticles through ball milling for a period range from 16 to 70 hours. Average size of their CNS nanoparticles at 70 hours is $56.03 \mathrm{~nm}$.

Findings from XRD study on CNS by (Bello et al., 2015a) have revealed CNS structures which are like observation in this present study. Also, sizes of PS particles fall between 0 and $148 \mathrm{~nm}$. Energy dispersive X-ray spectroscopic analysis indicates $\mathrm{Ca}$ as a major element of PS as shown in Figure 4. This element $(\mathrm{Ca})$ exists as carbonate as shown by XRD in Figure 10. A change in properties was observed after carbonization of the agricultural wastes as shown in Figures 5-7. Image of carbonized PKS particles in Figure 5 appears more fused together than what is observed in Figure 2 of uncarbonized PKS particles. Sizes of carbonised PKS particles fall between 0 and $160 \mathrm{~nm}$.

Carbon peak in Figure 5 is much higher than that in Figure 2. This can be attributed to distillation of the volatile components which has led to an increase in $\mathrm{C}$ counts. An increase in $\mathrm{C}$ content is compensated by reduction in the counts of the elements such as O. Similar observation was made in case of carbonized CNS and PS particles. This finding is in line with literature (Adebisi et al., 2017b, Bello et al., 2106, Bello et al., 2015a, Bello et al., 2015b).

Moreover, XRD peaks in Figure 8 show $\mathrm{Mg} 2 \mathrm{O} 4 \mathrm{Si}$, $\mathrm{Al} 2.7 \mathrm{CaCu} 0.83, \mathrm{Al} 0.56 \mathrm{Mg} 0.44$. These compounds represent mineral components of PKS and agree with findings from $\mathrm{XRD}$ in Figure 2. Presence of intermetallic compounds including $\mathrm{A} 12.7 \mathrm{CaCu} 0.83, \mathrm{~A} 10.56 \mathrm{Mg} 0.44$ is attributed to unavoidable chemical reaction between phases of uncarbonised PKS during ball milling process. Similar chemical reaction was disclosed in literature during refinement of CNS through ball-milling process (Bello et al., 
2015a, Bello et al., 2015b). Such chemical reaction is called mechanical alloying as found in literature (Chauruka et al., 2015, Maurice and Courtney, 1990, Qu et al., 2015). Similarly, $\mathrm{SiO} 2, \mathrm{Cu} 4 \mathrm{MgO} 5, \mathrm{Cu} 16 \mathrm{O} 14.5$ are observed with XRD peaks of uncarbonised CNS nanoparticles in Figure 9. These compounds affirm silica contents of CNS.

Presence of silica in organic wastes such as CNS, rice husk, cassava periderm and others has extensively been reported in literature (Romulo, 2013, Adebisi et al., 2017a, Adebisi et al., 2017b). Intermetallic $\mathrm{Cu} 4 \mathrm{MgO} 5$ and $\mathrm{Cu} 16 \mathrm{O} 14.5$ are attributable to unavoidable chemical reaction due to extremely high surface energy during particle refinement (Moreno and Ferrari, 2012, Pokropivny et al., 2007). Moreover, all peaks in Figure 9 indicate $\mathrm{CaCO} 3$. This finding agrees with earlier studies showing that snail, periwinkle and egg shells contain at least $85 \% \mathrm{CaCO}$. Remaining percentage may account for boron and nitrogen compounds (Agunsoye et al., 2015a, Agunsoye et al., 2015b, Agunsoye et al., 2016).
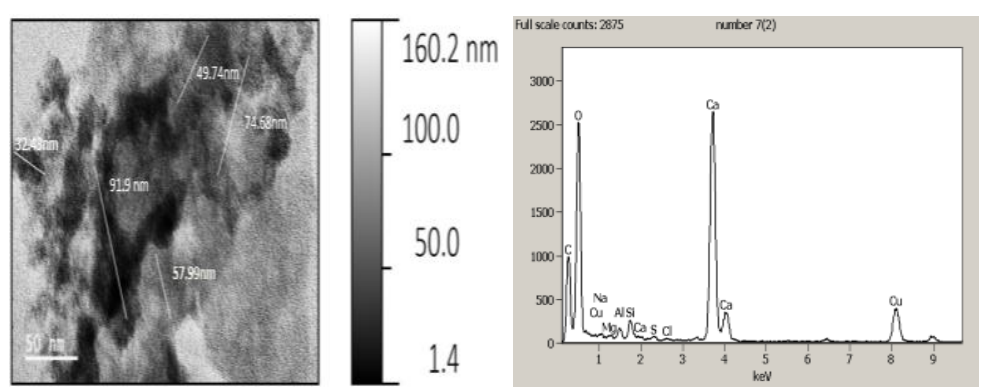

Figure 2: TEM/Gwyddion image showing size distribution/EDX of uncarbonized palm kernel shells nanoparticles.
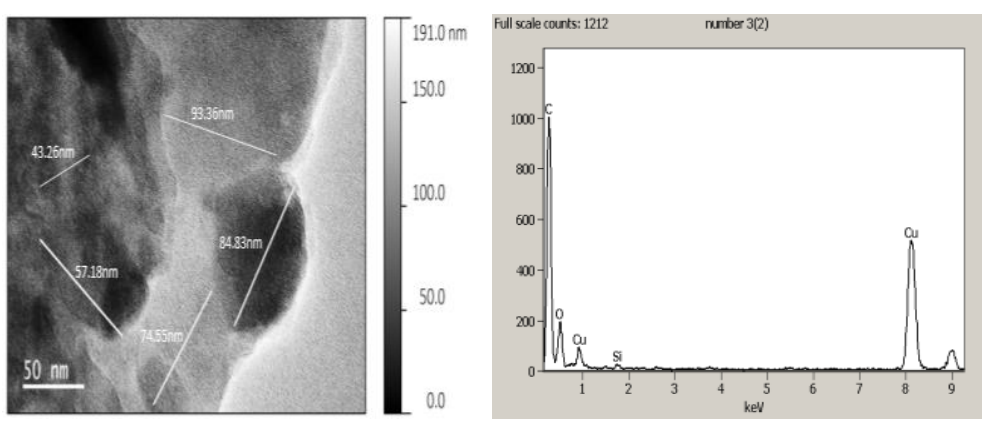

Figure 3: TEM/Gwyddion image showing size distribution/EDX of uncarbonized coconut shells nanoparticles.
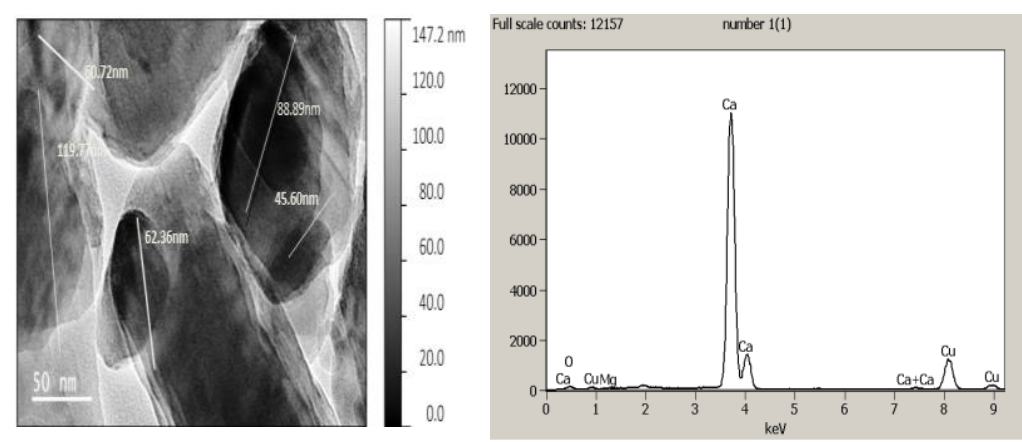

Figure 4: TEM/Gwyddion image showing size distribution/EDX of uncarbonized periwinkle shells nanoparticles process.
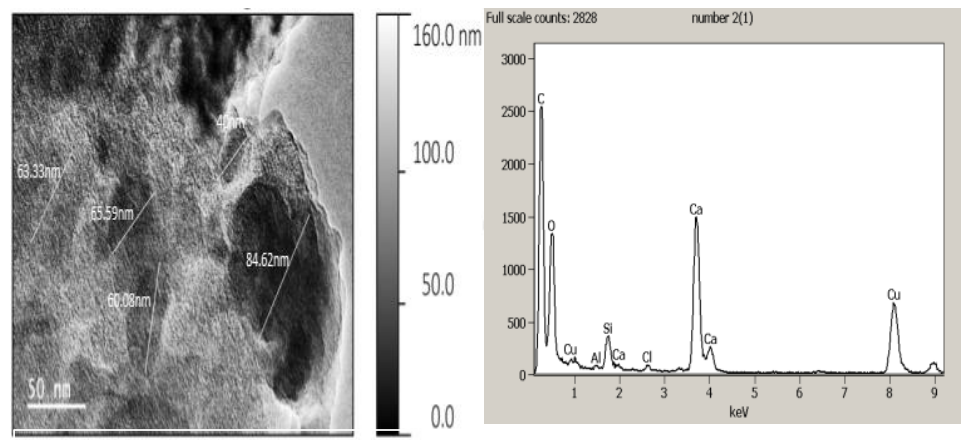

Figure 5: TEM/Gwyddion image showing size distribution/EDX of carbonized palm kernel shells nanoparticles.
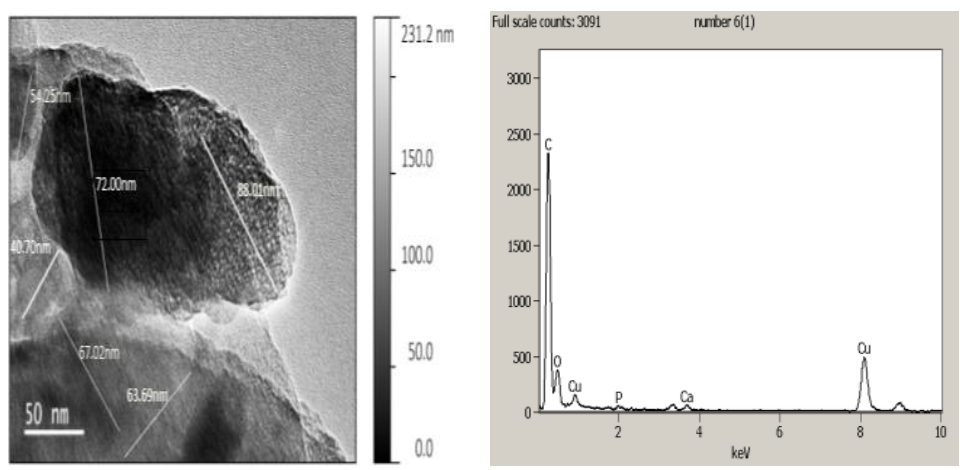

Figure 6: TEM/Gwyddion image showing size distribution/EDX of carbonized coconut shells nanoparticles.
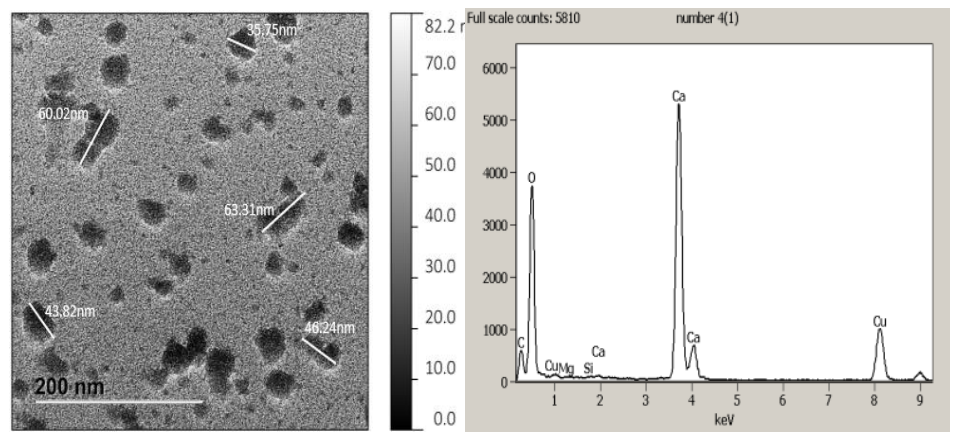

Figure 7: TEM/Gwyddion image showing size distribution/EDX of carbonized periwinkle shell nanoparticles.

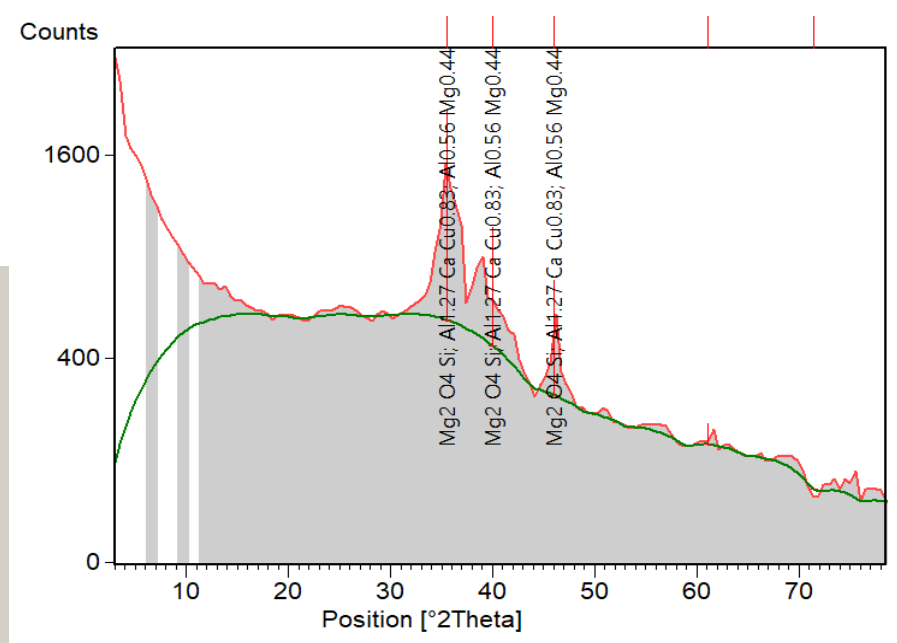

Figure 8: X-ray diffractogram of uncarbonized PKS nanoparticles. 


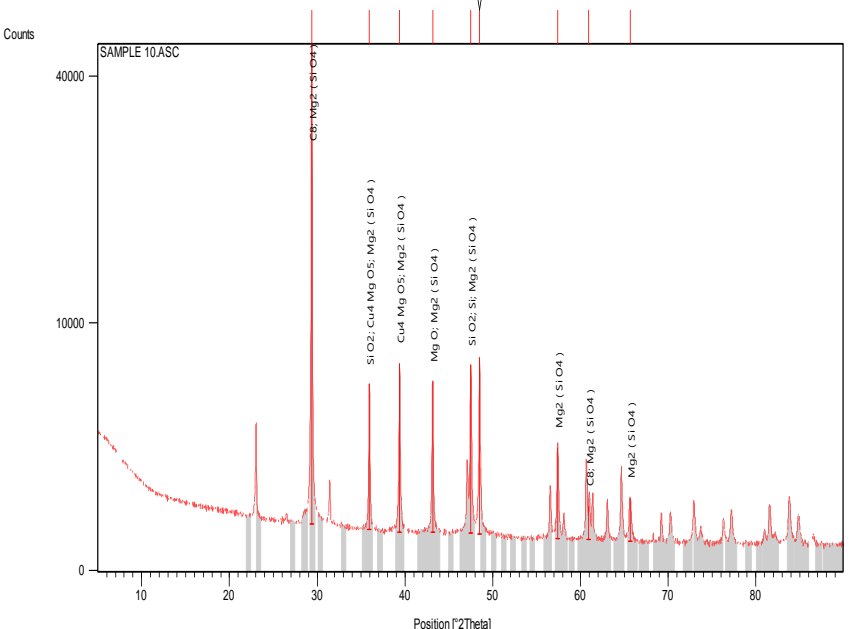

Figure 9: X-ray diffractogram of uncarbonized coconut shell nanoparticles.

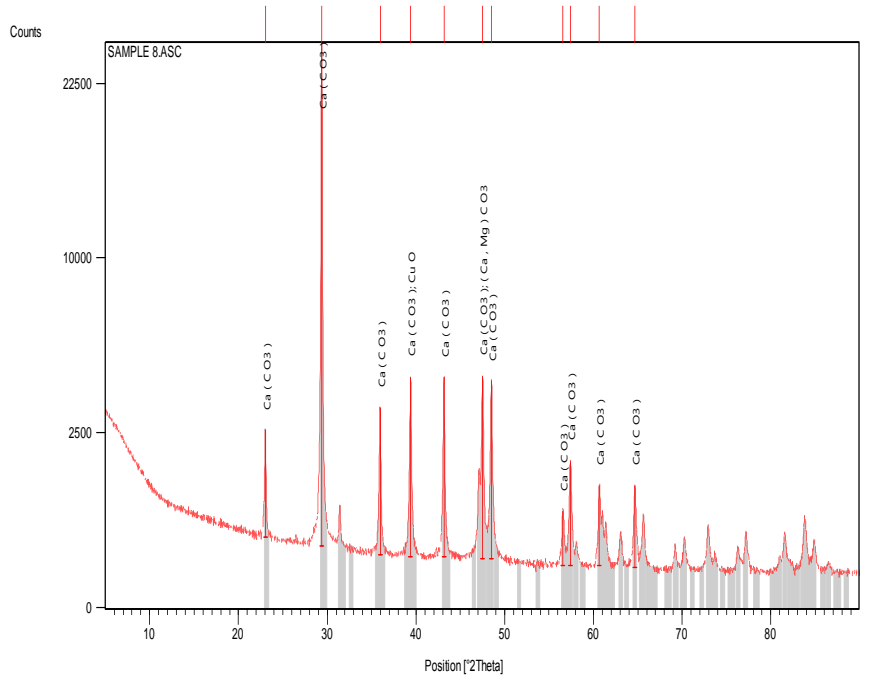

Figure 10: X-ray diffractogram of uncarbonized periwinkle shell nanoparticles.

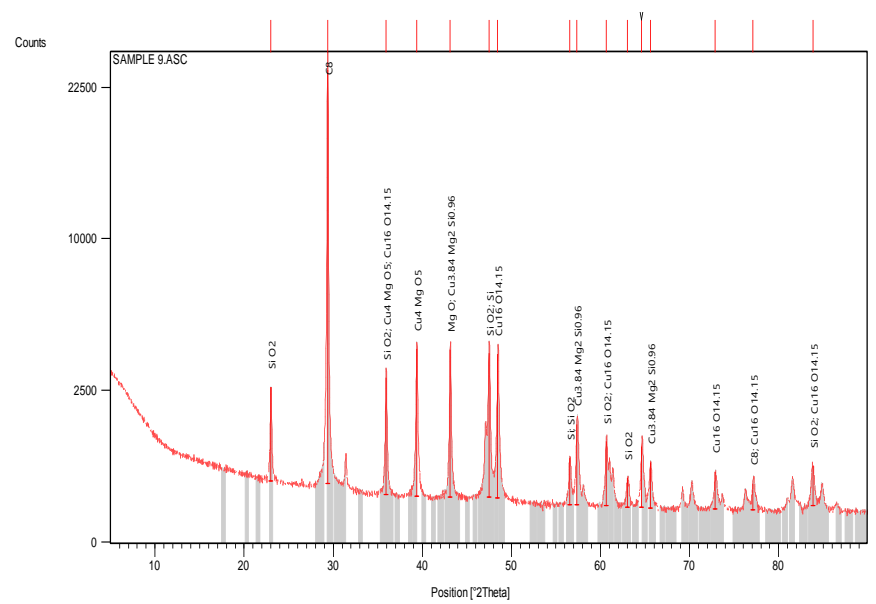

Figure 11: X-ray diffractogram of carbonized PKS nanoparticles.

Moreover, effect of carbonisation is shown on the PKS as phases indicated by XRD in Figure 11 are all oxides which probably formed from decomposition of mineral matter of the
PKS. Presence of $\mathrm{C}$, silicates, carbides and oxides in either uncarbonised or carbonised agricultural waste particles may be beneficial in enhancing the load bearing capacity of a matrix either metal or polymer into which the particles are intended to be incorporated, depending on sizes, weight or volume fr action of the particles and adhesion of the particles with the matrix (Ashori and Nourbakhsh, 2010, Atuanya et al., 2014). Since brittle and volatile components of the agricultural wastes have burnt off during carbonisation, carbonised PKS, CNS and PS nanoparticles may also enhance the toughness of the reinforced matrix as well (Akram et al., 2016).

The use of micro particles fillers for reinforcing aluminium alloys have been established in literature (Alaneme et al., 2016, Alaneme and Sanusi, 2015, Aigbodion et al., 2010), incorporation of PKS, CNS and PS nanoparticles fillers are expected to show much higher increase at lower weight or volume fractions because of higher hindrance to dislocation movements. A microparticles may have at least 100 nanoparticles when refined (Prasad Yadav et al., 2012). This implies that nanoparticle reinforcement of equal weight fraction with microparticles counterpart within a matrix has higher number of particles, leading to lower inter-planar spacing between nanoparticles reinforcement and higher packing density of the nanocomposites. It has established in literature that dislocation movement within the matrix becomes more difficult with higher packing densities (Lucas et al., 2011, William, 2007).

This makes the nanocomposites more strengthened than the micro composites having fewer particles within its matrix. Furthermore, Figure 12 compares the average sizes of the synthesised PKS, CNS and PS nanoparticles. As shown in Figure 12; PKS, CNS and PS exhibited different breakage tendencies under the same milling conditions. For 74 hours of milling at 10 charge ratios, all of them were refined to nanoparticle sizes, 56.52, 66.07, 62.89, 52.27, 64.28 and $49.23 \mathrm{~nm}$, respectively. $66.07 \mathrm{~nm}$ of CNS nanoparticles obtained in this research at 74 hours is in line with $56.03 \mathrm{~nm}$ of CNS nanoparticles obtained at 70 hours in literature (Bello et al., 2015a).

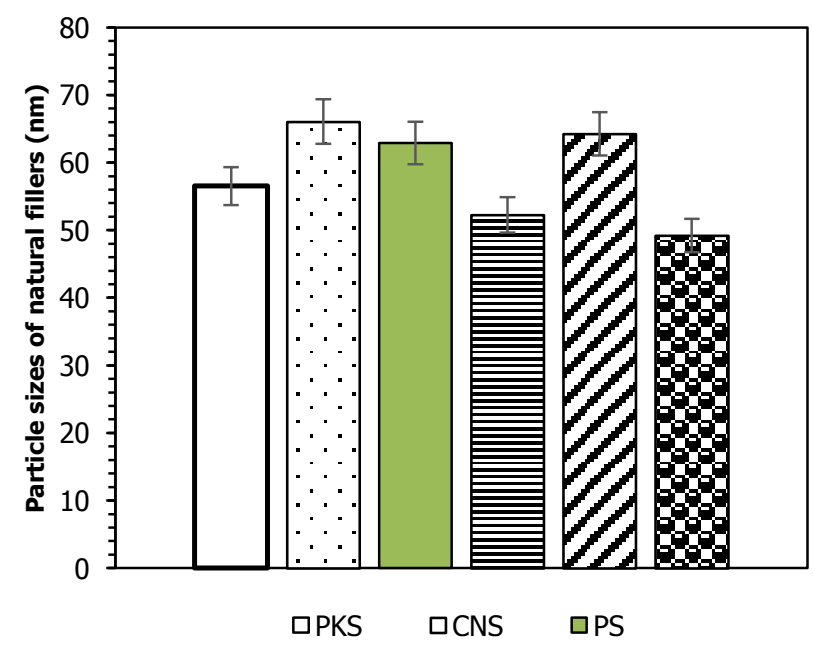

Figure 12: Comparison of sizes of uncarbonised and carbonized of synthesised agricultural waste particles. 
However, PKS has the least particle size indicating highest refinement abilities among other agricultural wastes used in this study. Excellent refinement property of PKS can be linked to presence of hard or brittle components of the PKS. After carbonization, refinement properties of all agricultural wastes increased. It is indicated by smaller sizes of carbonised agricultural waste particles than uncarbonised ones as shown in Figure 13. In this case, carbonised periwinkle shell particles (CPS) have least particle sizes. This observation is linked with phases of PS that are mainly $\mathrm{CaCO}_{3}$ which decomposes to brittle $\mathrm{CaO}$ while heating above $660^{\circ} \mathrm{C}$ in line with literature (Hunton, 2005).

\section{SUMMARY AND CONCLUSIONS}

Carbonized and uncarbonized nanoparticles of palm kernel, coconut and periwinkle shells have been synthesised from precursor powder of $45 \mu \mathrm{m}$ through continuous ballmilling for 74 hours at 10 charge ratios. Size determination indicated minimum size of $56.53 \mathrm{~nm}$ belonging to uncarbonized palm kernel shell among other uncarbonized agricultural wastes and $49.23 \mathrm{~nm}$ for carbonized periwinkle shells. Highest degree of refinement confirmed with carbonized periwinkle shell particles is linked to brittleness of $\mathrm{CaO}$ that may result from decomposition of $\mathrm{CaCO}_{3}$ during carbonization of periwinkle shells. Therefore, syntheses of palm kernel and periwinkle shells nanoparticles have been obtained and its effects on mechanical properties of aluminium metal matrix composites will be communicated in another article in future.

\section{$\mathrm{V}$ ACKNOWLEDGEMENTS}

Authors express their appreciation to Department of Metallurgical and Materials Engineering, University of Lagos; Ceramics Department, Federal Industrial Institute of Research Oshodi and Dr Victor Aigbodion, Department of Metallurgical and Materials Engineering, Nigeria University, Nsukka for their assistance in making this work successful.

\section{REFERENCES}

Abiko, H.; M. Furuse and T.Takano (2010). Reduction of Adsorption Capacity of Coconut Shell Activated Carbon for Organic Vapors Due to Moisture Contents. Industrial Health, 48 427-437.

Adebisi, J. A.; J. O. Agunsoye; S. A. Bello; I. I. Ahmed; O. A. Ojo; and S. B. Hassan (2017a). Potential of Producing Solar Grade Silicon Nanoparticles from Selected Agro-Wastes: A Review. Solar Energy, 142 68-86.

Adebisi, J. A.; J. O. Agunsoye; S. A. Bello; F. O. Kolawole; M. M. Ramakokovhu; M. O. Daramola; and S. B. Hassan (2017b). Extraction of Silica from Sugarcane Bagasse, Cassava Periderm and Maize Stalk: Proximate Analysis and Physico-Chemical Properties of Wastes. Waste and Biomass Valorization, in Press.

Ademoh, A. N., and Adeyemi, I. O. (2015). Development and Evaluation of Maize Husks (AsbestosFree) Based Brake Pad. International Institute for Science, Technology and Education (IISTE): Industrial Engineering Letters -IEL, 5 (2): 67-80.

Agunsoye, J. O.; S. A. Bello; S. I. Talabi; A. A. Yekinni; A. R. I.; D. O. A.; and E. I. T. (2015a). Recycled
Aluminium Cans/Eggshell Composites: Evaluation of Mechanical and Wear Resistance Properties. Tribology in Industry, 37 (1): 107-116.

Agunsoye, J. O.; S. A. Bello; A. A. Yekinni; I. A. Raheem and O. I. Awe (2016). Effects of Reinforcement Particle Sizes on Mechanical Properties of Aluminium/Egg Shell Composites. Unilag Journal of Medicine, Science and Technology, 4 (2): 133-143.

Agunsoye, J. O.; S. A. Bello; A. A. Yekinni; I. A. Raheem; M. M. Idehenre; T. E. Idegbekwu; and A. D. Oderinde (2015b). Potential of Recycled Aluminium Cans and $215 \mu \mathrm{m}$ Sized Eggshell Powder for Low Cost Metal Matrix Composites. Journal of Metallurgical Engineering, 4 (0): 24 .

Aigbodion, V. S.; S. B. Hassan; G. B. Nyior; and T. Ause (2010). Effect of Bagasse Ash Reinforcement on the Wear Behaviour of Al-Cu-Mg/Bagasse Ash Particulate Composites. Acta Metall. Sin.(Engl. Lett.), 23 (2): 81-89.

Akram, M.; I. Taha and M. M. Ghobashy, (2016). Potential of Carbon Particle Reinforced Polypropylene Formed in-Situ through the Pyrolysis of Carboxymethylcellulose. Composites Communications, 1 614.

Alaneme, K. K.; M. O. Bodunrin and A. A. Awe (2016). Microstructure, Mechanical and Fracture Properties of Groundnut Shell Ash and Silicon Carbide Dispersion Strengthened Aluminium Matrix Composites. Journal of King Saud University - Engineering Sciences, in Press.

Alaneme, K. K., and Sanusi, K. O. (2015). Microstructural Characteristics, Mechanical and Wear Behaviour Of aluminium Matrix Hybrid Composites Reinforced with Alumina, Rice Husk Ash and Graphite. Engineering Science and Technology, an International Journal, 18 (3): 416-422.

Alengaram, J. U.; M. Z.; Jumaat and H. Mahmud (2010). Structural Behaviour of Reinforced Palm Kernel Shell Foamed Concrete Beams. Challenges, Opportunities and Solutions in Structural Engineeringand Construction, Taylor \& Francis Group, London, Ghafoori (ed) 265-270.

Allaoui, A.; S. Bai; H. M. Cheng and J. B. Bai (2002). Mechanical and Electrical Properties of a Mwnt/Epoxy Composite. Composites Science and Technology, 62 (15): 1993-1998.

Ashori, A., and Nourbakhsh, A. (2010). Reinforced Polypropylene Composites: Effects of Chemical Compositions and Particle Size. Bioresour Technol, 101 (7): 2515-9.

Atuanya, C. U.; R. O. Edokpia; and V. S. Aigbodion (2014). The Physio-Mechanical Properties of Recycled Low Density Polyethylene (Rldpe)/Bean Pod Ash Particulate Composites. Results in Physics, 4 88-95.

Baghat, S., and Verma, P. K. (2013). Effects of Graphite Fillers on Mechnaical Behaviour of Epoxy Composites. International Journal of Emerging Technology and Advanced Engineering, 3 (2): 427-430.

Bello, S. A., J. O. Agunsoye; J. A. Adebisi; J. E. Anyanwu; A. A. Bamigbaiye and S. B.Hassan (2017a). Potential of Carbonised Coconut Shell as a Ball-Milling 
Interface for Synthesis of Aluminium (1xxx) Nanoparticles. Annals of Faculty of Engineering, 15 (2): 149-157.

Bello, S. A.; J. O. Agunsoye; J. A. Adebisi; F. O. Kolawole and B. H. Suleiman (2106). Physical Properties of Coconut Shell Nanoparticles. Kathmandu University Journal of Science, Engineering and Technology, 12 (1): 63-79.

Bello, S. A.; J. O. Agunsoye; J. A. Adebisi and B. H. Suleiman (2017b). Effects of Aluminium Particles on Mechanical and Morphological Properties of Epoxy Nanocomposites. Acta Periodica Technological, 48 25-38.

Bello, S. A.; J. O. Agunsoye and S. B. Hassan (2015a). Synthesis of Coconut Shell Nanoparticles Via a Top Down Approach: Assessment of Milling Duration on the Particle Sizes and Morphologies of Coconut Shell Nanoparticles. Materials Letters, 159 514-519.

Bello, S. A.; S. B. Hassan; J. O. Agunsoye; M. G. Z.; Kana and A, R. I. (2015b). Synthesis of Uncarbonised Coconut Shell Nanoparticles: Characterisation and Particle Size Determination Tribology in Industry, 37 (2): 257-263.

Bobic, B., Mitovic, S., Babic, M., and Bobic, I. (2010). Corrosion of Metal-Matrix Composites with Aluminum Alloy Substrate. Tribology in Industry, 32 (1): 3-11.

Chauruka, S. R.; A. Hassanpour; R. Brydson; K. J. Roberts; M. Ghadiri and H. Stitt (2015). Effect of Mill Type on the Size Reduction and Phase Transformation of Gamma Alumina. Chemical Engineering Science, 134 774783.

Chen, H.; O. Jacobs; W. Wu; G. Rüdiger and B. Schädel (2007). Effect of Dispersion Method on Tribological Properties of Carbon Nanotube Reinforced Epoxy Resin Composites. Polymer Testing, 26 (3): 351-360.

Das, S.; D. P. Mondal; S. Sawla; and N. Ramakrishnan (2008). Synergic Effect of Reinforcement and Heat Treatment on the Two Body Abrasive Wear of an Al-Si Alloy under Varying Loads and Abrasive Sizes. Wear, 264 (1): 47-59.

Edmund, C. O.; M. S. Christopher and D. K. Pascal (2014). Characterization of Palm Kernel Shell for Materials Reinforcement and Water Treatment. Journal of Chemical Engineering and Materials Science of sintering, 5 (1): 1-6.

Falade, F. (1992). The Use of Palm Kernel Shell as Coarse Aggregates in Concrete. Journal of Housing Science, 16 (3): 213-219.

Festus, A. O.; A. Q. Habeeb; and S. O. Oladipupo (2012). Investigation of the Strength Properties of Palm Kernel Shell Ash Concrete. Engineering, Technology \& Applied Science Research, 2 (6): 315-319.

Goto, H., and Uchijo, K. (2005). Wear Mechanism of Al-Si Alloy Impregnated Graphite Composite under Dry Sliding. Wear, 259 (1): 613-619.

Hunton, P. (2005). Research on Eggshell Structure and Quality: An Historical Overview. Brazilian Journal of Poultry Science, 7 (2): 67-71.
Ibhadode, A. O. A., and Dagwa, I. M. (2008a). Development of Asbestos-Free Friction Lining Material from Palm Kernel Shell Journal of the Brazilian Society of Mechanical Sciences and Engineering (J. Braz. Soc. Mech. Sci. \& Eng), 30 (2).

Ibhadode, A. O. A., and Dagwa, I. M. (2008b). Development of Asbestos Free Friction Lining Material from Palm Kernel Shell. Journal of the Brazilian Society of Mechanical Science and Engineering Failure Analysis, 30 (2).

Kok, M. (2005). Production and Mechanical Properties of Al2o3 Particle-Reinforced 2024 Aluminium Alloy Composites. Journal of Materials Processing Technology, 161 (3): 381-387.

Lucas, F. M. d. S.; Ö. Andreas and A. Robert (2011). Handbook of Adhesion Technology, Springer-Verlag Berlin Heidelberg.

Maurice, D. R., and Courtney, T. H. (1990). The Physics of Mechanical Alloying: A First Report. Met Trans A, 21 289-303.

Mohammed, L.; M. N. M. Ansari; G. Pua; M. Jawaid and M. S. Islam (2015). A Review on Natural Fiber Reinforced Polymer Composite and Its Applications. International Journal of Polymer Science, 201515.

Moreno, R., and Ferrari, B. (2012). Nanoparticles Dispersion and the Effect of Related Parameters in the Epd Kinetics.

Nwaobakata, C., and Agunwamba, J. C. (2014). Effect of Palm Kernel Shells Ash as Filler on the Mechanical Properties of Hot Mix Asphalt. Archives of Applied Science Research, 6 (5): 42-49.

Okoroigwe, E. C.; M. S. Christopher and Kamdem (2014). Characterisation of Palm Kernel Shell for Material Reinforcement and Water Treatment. Journal of Chemical and Materials Science, 5 (1): 1-6.

Pokropivny, V.; R. Lohmus; I. Hussainova; A. Pokropivny and S. Vlassov (2007). Introduction to Nanomaterials and Nanotechnology, Tartu University Press.

Prasad Yadav, T.; R. Manohar Yadav and D. Pratap Singh (2012). Mechanical Milling: A Top Down Approach for the Synthesis of Nanomaterials and Nanocomposites. Nanoscience and Nanotechnology, 2 (3): 22-48.

Qu, Y.; H. Luo; H. Li; and J. Xu (2015). Comparison on Structural Modification of Industrial Lignin by Wet Ball Milling and Ionic Liquid Pretreatment. Biotechnology Reports, 6 1-7.

Romulo, N. A. (2013). Market and Trade of Coconut Products. Thailand: Asian and Pacific Coconut Community.

William, D. C., Jr. (2007). Materials Science and Engineering an Introduction, United State of American, John Wiley \& Sons, Inc.

Yawas, D. S.; S. Y. Aku; and S. G. Amaren (2016). Morphology and Properties of Periwinkle Shell AsbestosFree Brake Pad. Journal of King Saud University Engineering Sciences, 28 (1): 103-109. 